Short Paper

\title{
Natural Reproduction of Coho Salmon Oncorhynchus kisutch Population Introduced in a Pond-Associated Stream in Hokkaido, Japan
}

\author{
Yoshinori Taniguchi, ${ }^{* 1}$ Hirokazu Urabe, ${ }^{* 1}$ and Shigeru Nakano*2 \\ ${ }^{*}$ Graduate School of Environmental Earth Science, Hokkaido University, Kita, Sapporo, Hokkaido 061, Japan \\ ${ }^{*}$ Tomakomai Research Station, Hokkaido University Forests, Takaoka, Tomakomai, Hokkaido 053, Japan
}

(Received December 15, 1995)

Key words: coho salmon, natural reproduction, pond-associated stream

Coho salmon Oncorhynchus kisutch are distributed on both the North American and Asian sides of the North Pacific coast, having the southern limits of their range around the Kamchatka Peninsula within the latter regions. ${ }^{\text {) }}$ All of native coho salmon populations typically have an anadromous life-cycle throughout their range. ${ }^{2)}$ Although coho salmon have been occasionally captured in,,$^{3,4)}$ or introduced into several freshwater systems in Japan, ${ }^{5}$ natural reproduction has not been found in any of these. Recently, we found that coho salmon introduced into a small pond-associated stream established a naturally reproducing population. As far as we know, this example is the first record of natural reproduction for coho salmon within freshwater systems in Japan.

Natural reproduction of coho salmon population was observed in the Horonai Stream $\left(42^{\circ} 40^{\prime} \mathrm{N}, 141^{\circ} 36^{\prime} \mathrm{E}\right)$, south-western Hokkaido, Japan. In 1988, the stream was experimentally stocked with approximately 4,000 hatchery reared coho salmon parr $\left(1_{+}\right)$, which had been obtained from parents imported from the State of Oregon, USA in 1983 (M. Saneyoshi: The Teikyo Univ. of Sci. Tech., pers. comm.). This cold spring-fed small stream (14 km long, 2$5 \mathrm{~m}$ wide and $<1 \%$ gradient) directly discharges into the Pacific Ocean running through the Tomakomai Experimental Forest (TOEF) of Hokkaido University (see Kitano et $\left.a l^{6}{ }^{5}\right)$. The stream reaches within TOEF are $5 \mathrm{~km}$ long and are characterized by having four artificial impoundments of 1.0 ha total area and 1-2.5 meters maximum depth. There are several damming structures, which are impassable for anadromous fish migrating upstream, in the downstream reaches of TOEF.

In the stream reaches, including the impoundments, within TOEF, intensive fish population surveys have been conducted with several gear types, e.g. electrofishing units (in the stream reaches) and gill nets (in the ponds), since 1990. During the survey, three coho salmon parr were captured on October 25, 1993, and four on September 27, 1994. In addition, nine adults, one of which was a carcass, were obtained during November 8-14, 1995 (Fig. 1). We examined the age (using both otolith and scales), gonadal maturity, and meristic and morphometric characteristics of these fish samples.

The ages of all the seven parr and nine adults were $0_{+}$ and $3_{+}$, respectively. The values of both meristic and morphometric characteristics lay within the range documented for lacustrine populations in the Cultus Lake in British Columbia, Canada ${ }^{2)}$ and anadromous ones around the $\mathrm{Ku}$ ril Islands, North Pacific ${ }^{4}$ (Table 1). However, the mature adults in the Horonai Stream were considerably smaller than those reported for these populations. Both the male and female adults exhibited a grey or black abdomen and dark-brown body with dense black spots but not a bright spawning coloration (like red lateral sides) typical to anadromous coho salmon. Both male $(n=3)$ and female $(n=6)$ adults retained ripe gonads in just the pre- or postspawning stages. Coho salmon spawn from September through October in Cultus Lake in Canada and from October through November in the Kuril Islands. All of the adults were captured in an immediately upstream reach of a pond inlet, where five completed spawning redds and two spawning activities were observed during November 5-14. In contrast, the sampling locations of the parr were distributed from the lowermost reaches to the headwater of the stream but never in the ponds.

Coho salmon transplanted into the Great Lakes (freshwater system) in eastern North America, for example, have established a lacustrine life-cycle; they migrate down to a lake after one or more years of stream-life, spend about two years in the lake, then spawn in the stream primarily at the age 3 or $\left.4{ }_{+} .{ }^{7}\right)$ We assume that, in the Horonai Stream, the coho salmon parr stocked in 1988 grew and reproduced naturally in the following years. They appear to have established a similar lacustrine lifecycle in which they utilize the far smaller impoundments as growing space in place of lakes. The sampled parr and adults may be second or third generations.

We believe that given a pond environment and coldwater nursery stream, coho salmon have a great potential to establish a naturally reproducing population even in freshwater systems south of their distribution margin. Studies exploring competitive interactions between introduced coho salmon and native salmonids have generally found that they use similar niches and compete strongly for limited resources in the Great Lakes tributaries. ${ }^{8)}$ As a consequence, populations of native species have declined in abundance and been displaced from much of their range. The Horonai Stream historically has not been inhabited by any native salmonid fish. Coho salmon introduced to other natural habitats, however, have the potential to increase in abundance and eliminate native 


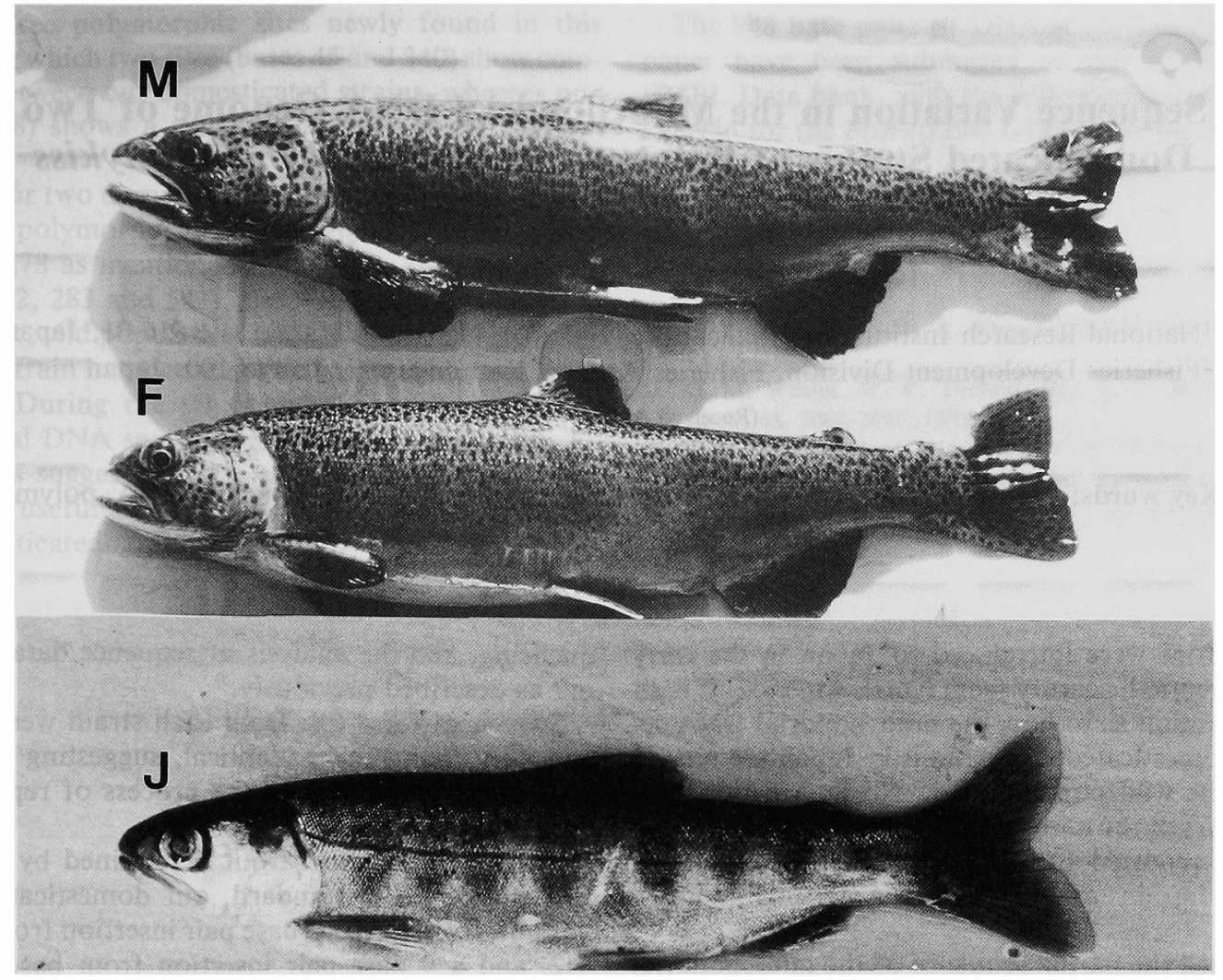

Fig. 1. Male (M; $330 \mathrm{~mm}$ in standard length), female (F; $300 \mathrm{~mm})$ adults, and juvenile (J; $95.9 \mathrm{~mm})$ Oncorhynchus kisutch collected in the Horonai Stream, southwestern Hokkaido, Japan.

Table 1. Meristic and morphometric characteristics of juvenile and adult Oncorhynchus kisutch from the Horonai Stream, Hokkaido, Japan and other regions

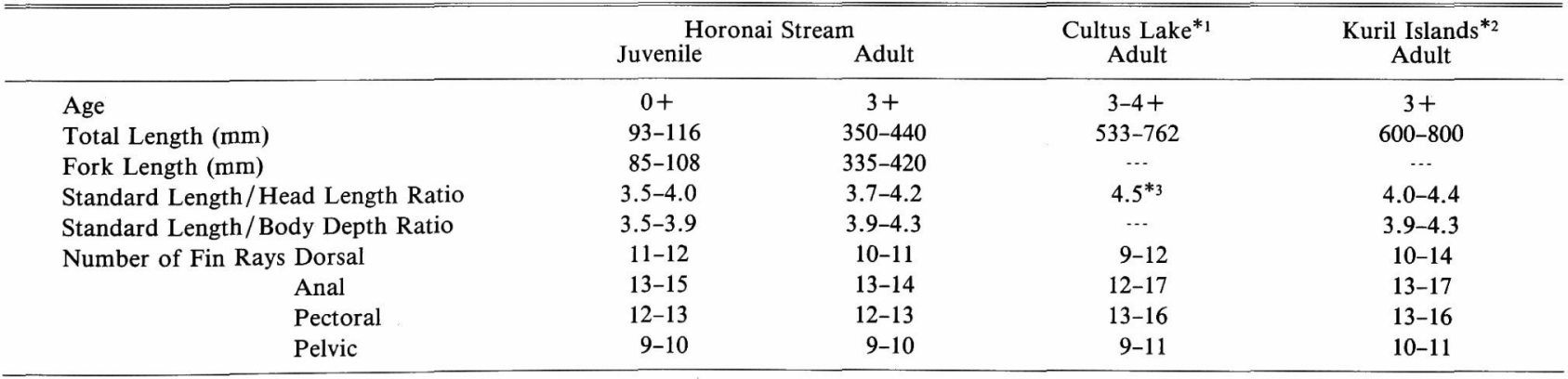

${ }^{*_{1}}$ Scott and Crossman. ${ }^{2)}{ }^{*_{2}}$ Miyadi et al. ${ }^{4)}{ }^{*_{3}}$ The value was based on total length/head length.

salmonid in freshwater systems in Japan.

Acknowledgments We thank Drs. K. Ishigaki and M. Saneyoshi for their constructive comments. We also wish to thank E. Fujito, Y. Kawaguchi, Y. Shibata, H. Miyasaka, and T. Ishii for their field assistance. This study was supported partly by a grant-in-aid (No. 07306022 and 07308042) from the Ministry of Education, Science and Culture of Japan.

\section{References}

1) F. K. Sandercock: in "Pacific salmon life histories" (ed. by C. Groot and L. Margolis), UBC Press, Vancouver, Canada 1991, pp. 395445.

2) W. B. Scott and E. J. Crossman: Freshwater fishes of Canada, Fisheries Research Board of Canada, Ottawa, Canada, 1973, pp. 158-
164.

3) T. Hikita: Sci. Rep. Hokkaido Salmon Hatchery, 17, 1-97 (1962).

4) D. Miyadi, H. Kawanabe, and N. Mizuno: Coloured illustrations of the freshwater fishes of Japan, Hoikusha Publishing, Co., Ltd., Osaka, Japan, 1976, pp. 94-95 (in Japanese).

5) A. Ishida, T. Tanaka, S. Kameyama, K. Sasaki, and Y. Nemoto: Sci. Rep. Hokkaido Salmon Hatchery, 29, 11-15(1975).

6) S. Kitano, S. Nakano, M. Inoue, K. Shimoda, and S. Yamamoto: Nippon Suisan Gakkaishi, 59, 1837-1843 (1993).

7) W. R. Meehan and T. C. Bjornn: in "Influences of forest and rangeland management of salmonid fishes and their habitats" (ed. By W. R. Meehan), American Fisheries Society Special Publication, Bethesda, Maryland, USA, 1991, pp. 47-82.

8) K. D. Fausch and R. J. White: Trans. Amer. Fish. Soc., 115, 363381 (1986). 